Article

\title{
Investigations on Graphene Platelets as Dry Lubricant and as Grease Additive for Sliding Contacts and Rolling Bearing Application
}

\author{
Florian Pape *(D) and Gerhard Poll \\ Institute of Machine Design and Tribology, Leibniz University Hannover, Welfengarten 1A, 30167 Hannover, \\ Germany; poll@imkt.uni-hannover.de \\ * Correspondence: pape@imkt.uni-hannover.de; Tel.: +49-511-762-5552
}

Received: 6 November 2019; Accepted: 17 December 2019; Published: 19 December 2019

check for updates

\begin{abstract}
In recent years, graphene-based lubrication was in the focus of nano- and microtribological studies. While the sliding properties of graphene based dry lubrication were previously investigated on the nano- and micro-scale, few studies can be found in the literature for the application of graphene as an additive to oil and grease in rolling contacts. In order to apply graphene platelets as dry lubricants and as grease additives in machine elements, tests were carried out on a rolling bearing test rig under typical load conditions. For these investigations, multilayer graphene platelets of varied staple thickness were functionalized on angular contact ball bearing surfaces as a dry lubricant, which forms a thin film. In addition, bearings were lubricated with grease containing graphene platelets. In this case, a small ratio of graphene was dispersed with grease. The graphene platelets were divided into three groups of different thickness: $2 \mathrm{~nm}, 6-8 \mathrm{~nm}$, and 11-15 nm. Additionally, the tests were compared to graphite nanoparticles (spheres with a size of 3-4 nm) as dry lubricant and graphite-containing grease. The experimental studies were carried out under oscillating motion. The respective load in the tribological contact was $1.5 \mathrm{GPa}$. During the tests, the pivoting angle was measured by utilizing a rotary encoder. In addition, the friction torque was recorded under a frequency of $0.2 \mathrm{~Hz}$. As the balls' velocity at the reversal point is zero, the lubrication conditions are critical. The dry lubricated bearings were compared to grease lubricated bearings. Additionally, the frictional properties of the respective greases were investigated by applying a sliding tribometer. In this case, a ball rotates against three contact planes, which causes a tribological contact under a contact pressure of $1 \mathrm{GPa}$. It was shown that applying graphene as a dry lubricant and as a grease additive under rolling contact conditions reduces friction significantly.
\end{abstract}

Keywords: graphene; nano particles; grease lubrication; dry lubrication; rolling contact

\section{Introduction}

Graphene, as an allotrope of carbon, features two-dimensional (2-D) layers consisting of covalently bonded carbon atoms. It offers excellent sliding properties comparable to graphite. Graphene features a high thermal conductivity [1] and a high electrical conductivity [2].

The tribological benefit of graphene could be proven in earlier studies, particularly for sliding contacts [3-7]. Bermann et al. investigated the friction properties of graphene in sliding contacts and proved that graphene in ethanol solution can effectively reduce friction [4]. Marchetto et al. demonstrated the excellent lubrication properties of graphenized surfaces by utilizing a sphere-on-flat tribometer [5]. By applying a microtribometer, Kim et al. investigated the friction properties of graphene as a dry lubricant [6]. In particular, the friction and wear properties of graphene were investigated on the nano- and microscale by atomic force microscopy (AFM) [8,9]. Frank and Tanenbaum analyzed the 
mechanical properties of graphene plate stacks, applying an AFM and determining the spring constant and a Young's modulus of $0.5 \mathrm{TPa}$ [10]. Restuccia et al. investigated the tribochemistry of graphene on iron and showed that graphene binds strongly to iron surfaces and reduces the surface energy. It was shown that the metal surfaces are nearly inert due to passivation effects and have very low adhesion and shear strength when joined in a sliding contact [11]. The durability of graphene in dry sliding contact on $\mathrm{Cu}$ substrates was demonstrated by Won et al., utilizing a reciprocating tribotester with a contact pressure of approximately $220 \mathrm{MPa}$ to investigate graphene on $\mathrm{Cu}$. The graphene coatings with a thickness of a few layers could effectively increase the durability of the Cu substrate under dry sliding contact [12].

For the processing of graphene, some solvents have proven their suitability for dispersing graphene platelets in an ultrasonic bath. The graphene can then be applied to surfaces under the influence of thermal energy. Paredes et al. have investigated various solvents to disperse graphene. Besides ethylene and tetrahydrofuran (THF), methyl-2-pyrrolidone (NMP) and N, N-dimethylformamide (DMF) are possible solvents [13].

For sliding steel contacts, Lr et al. studied the effect of graphene in 4-n-pentyl-4'-cyanobiphyl liquid crystal [14]. It was also shown that the graphene forms a protective surface layer between the sliding surfaces and could reduce friction and wear.

The tribological properties of graphene oxide nanoplatelets in mineral oils under boundary and mixed lubrication, as well as elasto-hydrodynamic regimes, were investigated by Senatore et al. It was shown that graphene oxide nanoplatelets as a lubricant additive form a protective film, prevent direct contact between the steel surfaces and improve the frictional behavior of the base oil [15]. Multi-layered graphene as an additive to PAO2 oil was studied by Guo and Zhang [16]. The tests were performed in a four-ball assembly, showing a reduction of $78 \%$ of the coefficient of friction and also a reduction in wear. Zhang et al. also investigated graphene as an additive in oil (PAO9 oil) in a four ball tribometer and achieved reduced friction compared to pure oil [17].

In the case of graphene-based grease, some studies from recent years proved to have beneficial lubricating properties. Singh et al. investigated lithium grease with reduced graphene oxide as an additive in a ball-on-disc test rig with Hertzian pressure of up to 1.2 GPa [18]. It was shown that the coefficient of friction could be reduced. It is estimated that the layered structure of the graphene oxides facilitates easy shearing between roughness contacts. Missala et al. studied lithium grease containing graphene platelets under sliding contact conditions and relatively low contact pressure of 2.2 $\mathrm{MPa}$ [19]. In the tests, friction and wear were reduced by using graphene platelets as an additive. Liu et al. reviewed the benefits of graphene and other 2D materials as lubricant additives and suggests that these kind of materials feature beneficial interfacial friction and surface friction mechanisms [20].

Recent review papers on the application of graphene in tribology proved that the missing perspective on applying graphene as dry lubricant to machine elements is on the macro scale $[9,21]$. The research on the nano- and micro scale enables the discovery of new methods to insert graphene as dry lubricant on rolling bearing surfaces. The test results are compared to grease and graphene grease lubricated rolling bearings.

\section{Materials and Methods}

In this study, thin graphene platelets were used as a dry lubricant and as an additive in greases for sliding and rolling contacts. The investigations were first performed for the graphene-additivated grease in a sliding contact tribometer. In a second step, the graphene grease and dry lubrication were examined on a bearing test rig for rolling contact conditions. Graphene is applied on bearing steel as platelets with a diameter in the $\mu \mathrm{m}$ range and a thickness of a few $\mathrm{nm}$ featuring sliding surfaces. The graphene platelets were purchased as samples of defined thickness and represent several graphene sheet layers. For comparison, spherical graphite nano powder with a size in the range of $3 \mathrm{~nm}$ was investigated as a grease additive and dry lubricant. The difference in the graphene platelets is that the platelets function as a 2-D material that covers asperities and features larger 
sliding planes. For the investigations on graphene-additivated grease, graphene platelets were stirred into a defined quantity of grease to achieve a concentration of $1 \mathrm{wt} \%$ graphene platelets into the grease. In our case, samples were prepared by applying graphene platelets with thicknesses of $2 \mathrm{~nm}$, 6-8 $\mathrm{nm}$, and 11-15 $\mathrm{nm}$ to the specific grease samples with a spatula. A barium complex soap thickened synthetic hydrocarbon-based grease was inserted. Additional graphite nanoparticles with a size of 3-4 nm were stirred into a grease sample with a concentration of $1 \mathrm{wt} \%$. The process of stirring was finished when the grease was uniformly dark colored. Next, it was filled into a syringe to grease the respective surfaces.

For the application of graphene as a dry lubricant, N, N-dimethylformamide (DMF) was used to deagglomerate graphene platelets and graphite nanoparticles and to apply the platelets and particles to the bearing surfaces [22,23]. For the investigation, graphene platelets of three different thicknesses were applied: $2 \mathrm{~nm}, 6-8 \mathrm{~nm}$, and 11-15 nm. The spherical graphite nanoparticles were 3-4 nm in size.

The processing of the graphene as a dry lubricant is illustrated in Figure 1. In a first step, DMF was filled into a beaker. To reduce agglomerates and to obtain a good suspension, the mixture was treated in an ultrasonic bath for $2 \mathrm{~h}$. In earlier studies on the suspension of nanoparticles, it was demonstrated that this duration is sufficient to achieve good decomposition of the nanoparticle agglomerates [24]. For the next step, the suspension was applied as a thin layer on the raceways and rolling elements of the bearings. The bearing rings and rolling elements were heated in an oven at $120{ }^{\circ} \mathrm{C}$ for $5 \mathrm{~min}$. Figure 2 shows the graphene platelets on the bearing surface. Next, the bearing cage, the rolling elements, the inner ring, and the outer ring were assembled. Finally, the bearings were installed in the test bench and the investigation was executed. After the test, the bearings were disassembled and examined by laser scanning microscopy.

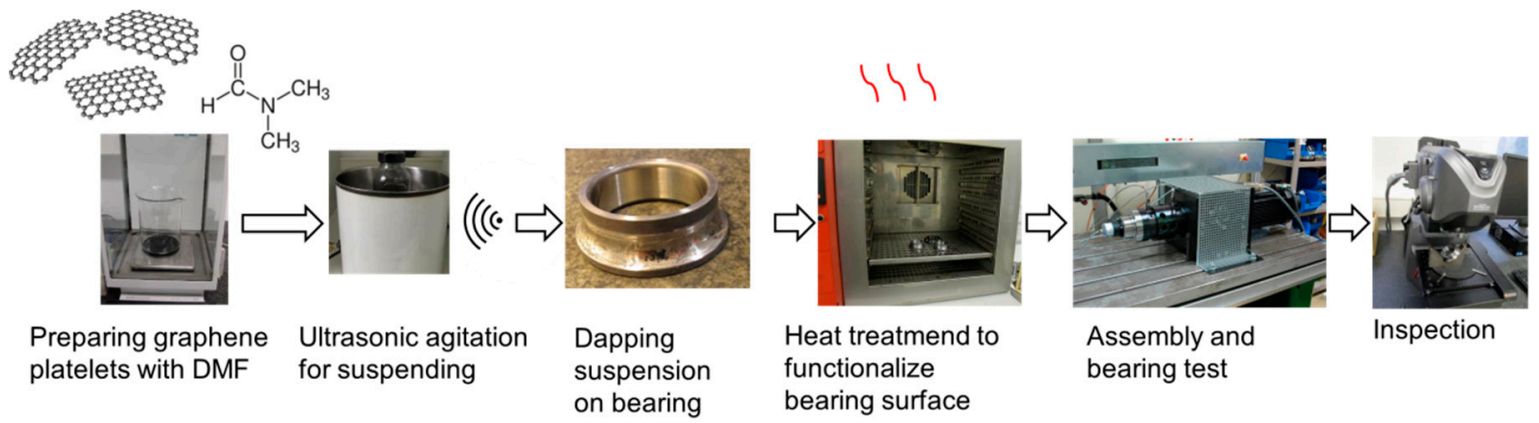

Figure 1. Process chain for investigation of graphene dry-lubricated angular contact ball bearing.

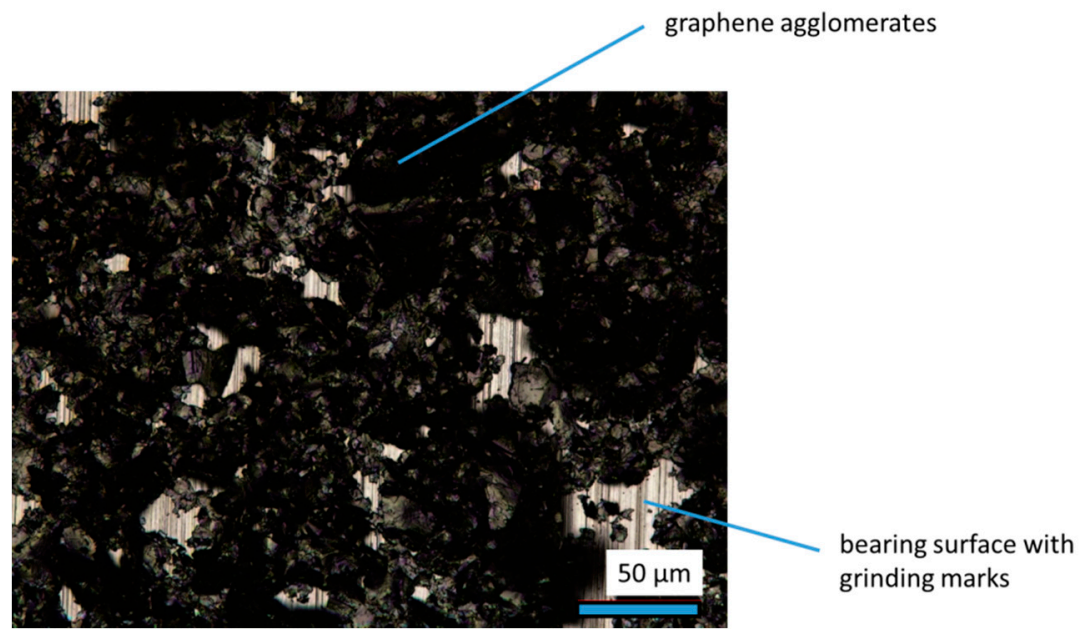

Figure 2. Angular contact ball bearing surface coated with graphene platelets as a dry lubricant. 
To investigate the influence of graphene as an additive to grease, the frictional properties under sliding contact conditions were examined with an Anton Paar tribometer (MCR302, Graz, Austria) (Figure 3). In the design, a ball is rotated against three circularly arranged cylinders under a defined contact pressure $(1 \mathrm{GPa})$. In this way, three point contacts are realized under sliding contact conditions. The ball was rotated at a speed of up to $1 \mathrm{~m} / \mathrm{s}$ and the friction force was measured.

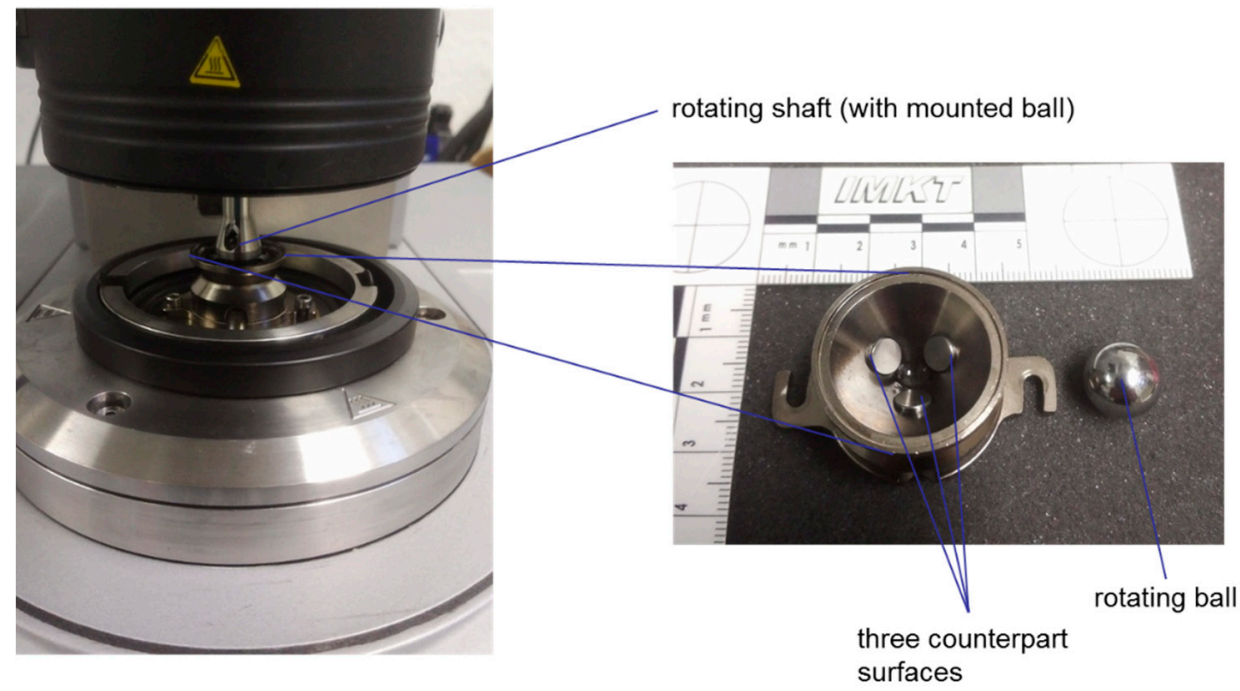

Figure 3. Anton Paar MCR Tribometer, tests performed under contact pressure of $1 \mathrm{GPa}$.

The graphene grease and graphene dry-lubricated bearings were investigated on a two bearing test rig, as shown in Figure 4. The test bench allows the investigation of two angular contact ball bearings simultaneously, which are mounted in a back-to-back arrangement. For the tests, modified angular contact ball bearings 7208, with the main dimensions according to DIN 628-1 (contact angle $\alpha=40^{\circ}$ ), and a reduced number of rolling elements were used. The number of rolling elements was reduced from 14 to 7 to allow for larger pivoting angles. These bearings have an inner and an outer ring, each with a raceway. The surface roughness of the raceways features a value of $R_{a}=0.19 \mu \mathrm{m}$; for the rollers the roughness is $R_{a}=0.07 \mu \mathrm{m}$. The rolling elements roll in a polyamide cage. Typically, the bearings are used for a higher speed rotational motion, in our case, the bearings were tested under oscillating motion. For this kind of bearing, a rolling motion is superimposed by a spinning moment perpendicular to the contact plane. On the contact area, a sliding friction component occurs, resulting in a rolling of the bearing with a small sliding ratio. A constant pivoting angle of $48^{\circ}\left( \pm 24^{\circ}\right)$ was used for the tests. The pivoting motion is based on the idea of later application of the graphene dry lubrication and graphene grease for constant velocity joint shafts in the transportation sector or robot arms. The bearings were grease lubricated with $8 \mathrm{~mL}$ Barium complex, soap-thickened, synthetic hydrocarbon-based grease, as well as with graphene additivated grease, and dry lubricated with functionalized graphene platelets as a coating on the raceways and rolling elements. The contact pressure between the inner ring and the rolling elements of the axially loaded bearings was $1.5 \mathrm{GPa}$.

A servo motor was used to perform an oscillating motion. A rotating torque sensor was coupled to the shaft between the servo motor and the test head with the bearings. For long-term tests, a normal shaft was used instead of the torque-measuring shaft to achieve a higher torsional stiffness. A rotary encoder was connected to the main shaft to measure the pivoting angle of the oscillating bearings. The friction torque was recorded at a frequency of $0.2 \mathrm{~Hz}$ for a duration of $3 \mathrm{~h}$. The torque measurement was made at a lower pivoting frequency due to the sensitive torque-measuring shaft. This was followed by a duration test of more than 1 million cycles at $5 \mathrm{~Hz}$ using a stiff shaft instead of the rotating torque sensor. After testing, the bearings were investigated by microscopy. 


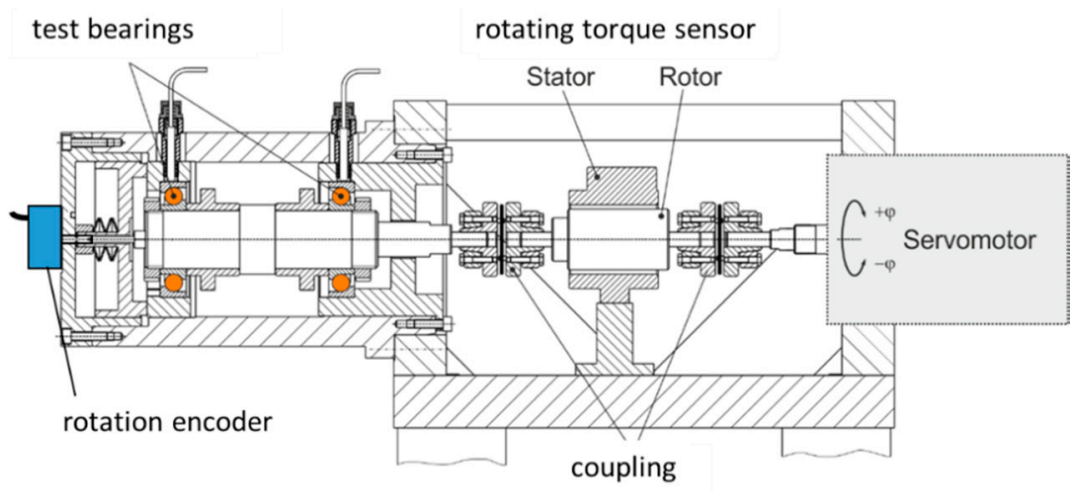

Figure 4. Test rig for two opposite arranged angular contact ball bearings.

\section{Results}

In order to examine the influence of graphene as an additive to grease in sliding contacts, tests were carried out with the Anton Paar tribometer. In this case, a sliding contact with a contact pressure of $1 \mathrm{GPa}$ occured. During the test, the rotational speed was increased up to $1 \mathrm{~m} / \mathrm{s}$. The resulting Stribeck curve for the graphene-additivated grease is shown in Figure 5. The graphene as an additive to grease could effectively reduce the friction at very low speeds, while the friction increased slightly at higher sliding speeds of up to $1 \mathrm{~m} / \mathrm{s}$ in comparison to the reference grease curve. The graphite nanoparticles as a grease additive shows only slight differences to the reference grease curve. The graphene platelets seem to have favorable sliding planes, especially for low relative velocities. It should be noted that the main difference of the graphite and graphene platelets can be found in the shape of the material. While the graphite powder has a spherical shape the graphene platelets have a diameter in the range of a few microns and feature 2-D sliding planes on the surface. For the low sliding speeds, the 2-D sliding planes of the graphene platelets can cover surface asperities and feature sliding planes.

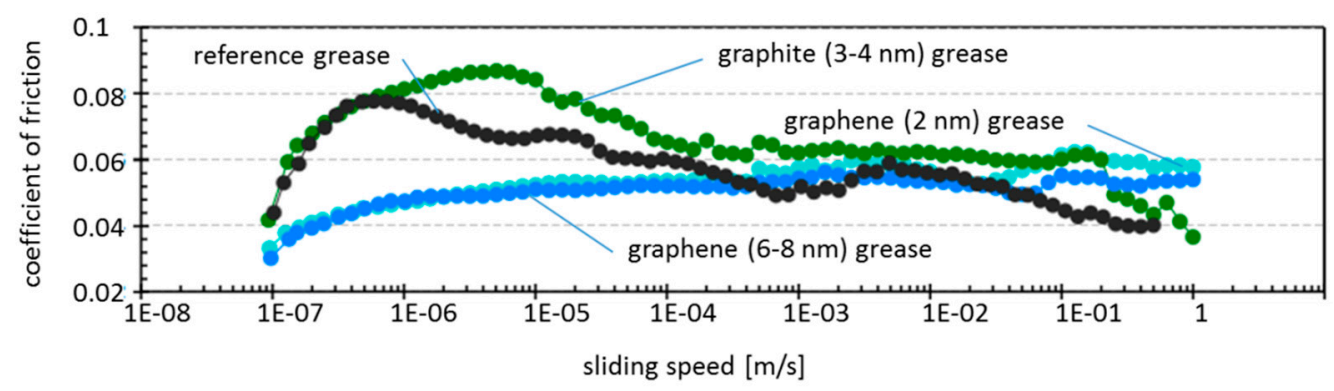

Figure 5. Coefficient of friction for graphene grease and graphite grease in sliding tests.

In order to reach a conclusion regarding the frictional properties of the graphene as a grease additive and dry lubricant for rolling contacts, the frictional torque for pivoting movement was investigated in a bearing test rig. The measurement of the frictional torque was carried out directly at the beginning of the bearing tests (for a duration of $3 \mathrm{~h}$ ) at a test frequency of $0.2 \mathrm{~Hz}$. After the frictional torque measurement, the tests were continued for more than 1 million test cycles under $5 \mathrm{~Hz}$. Figure 6 shows the average values of the frictional torque over the pivoting angle of $\pm 24^{\circ}$ for the graphene platelets, depending on the thickness. While the friction torque for the grease-lubricated bearing has average values of $\pm 150 \mathrm{Nmm}$, the frictional torque for the graphene grease-lubricated bearings could be cut to half for the graphene grease with a thickness of $11-15 \mathrm{~nm}$ and $2 \mathrm{~nm}$, as well as for the graphite nanoparticles (thickness of 3-4 nm) as a grease additive. In case of the graphene platelets with a thickness of 6-8 nm, the frictional torque could be reduced by a factor of approximately five. 


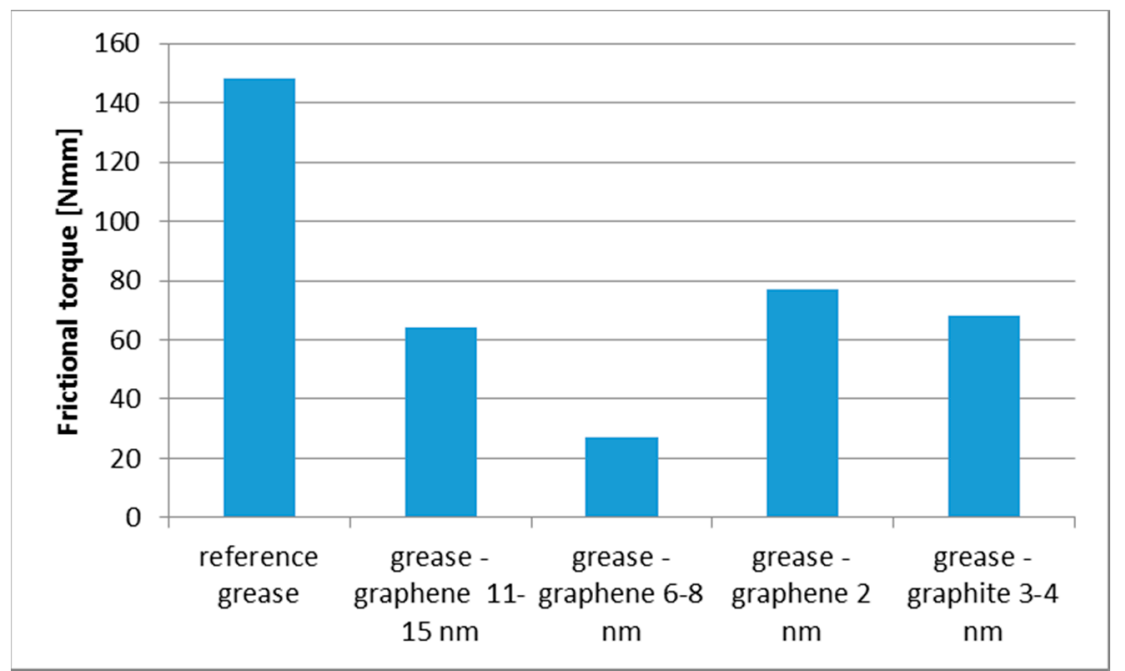

Figure 6. Two bearing test rig-average frictional torque for graphene grease and graphite grease-lubricated bearings under oscillating motion $\left( \pm 24^{\circ}\right)$.

The measurements for the graphene platelets and graphite nanoparticles as a dry lubricant are presented in Figure 7. In the case of the graphene and graphite as a dry lubricant, the frictional torque was reduced drastically compared to grease lubrication. The frictional torque for the graphene platelets with a thickness of 11-15 nm shows a reduced frictional torque with an average value of $\pm 70 \mathrm{Nmm}$. For the graphene platelets with a thickness of $2 \mathrm{~nm}$, the frictional torque features a value of approximately $\pm 32 \mathrm{Nmm}$; the graphene platelets with a thickness of 6-8 $\mathrm{nm}$ feature a frictional torque of approximately $\pm 13 \mathrm{Nmm}$. In comparison, the graphite nanoparticles feature a frictional torque of $\pm 23 \mathrm{Nmm}$.

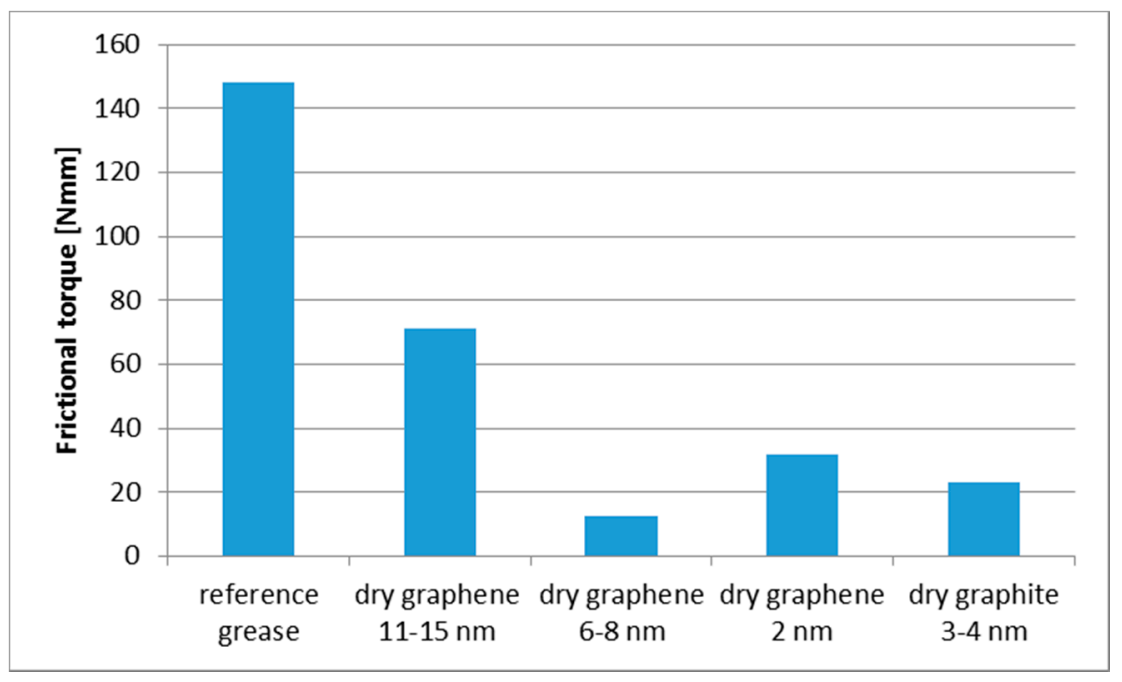

Figure 7. Two bearing test rig-average frictional torque for graphene and graphite dry-lubricated bearings under oscillating motion $\left( \pm 24^{\circ}\right)$.

Pairs of grease-lubricated, graphene grease, and graphene dry-lubricated angular contact ball bearings were tested for more than 1 million test cycles on the bearing test rig to investigate the changes on the surfaces at the reversal points. Due to the pivoting movement, mixed friction can occur, especially at the reversal points, which can lead to wear. The topology of the raceway surface after testing was examined by laser scanning microscopy.

First, a test was carried out to examine a grease-lubricated bearing pair. After more than 1 million test cycles, corrosion and slight wear could be detected at the reversal points on the raceway (Figure 8). 
At these points, the relative motion of the rolling elements is zero and the lubrication film thickness is lowest. In this case, lubrication is essential to avoid wear. Due to mixed lubrication conditions under a low relative velocity, asperities can be in contact and wear, and fretting corrosion can be detected. Also, a change in the color of the surface can be detected based on tribofilm formation.

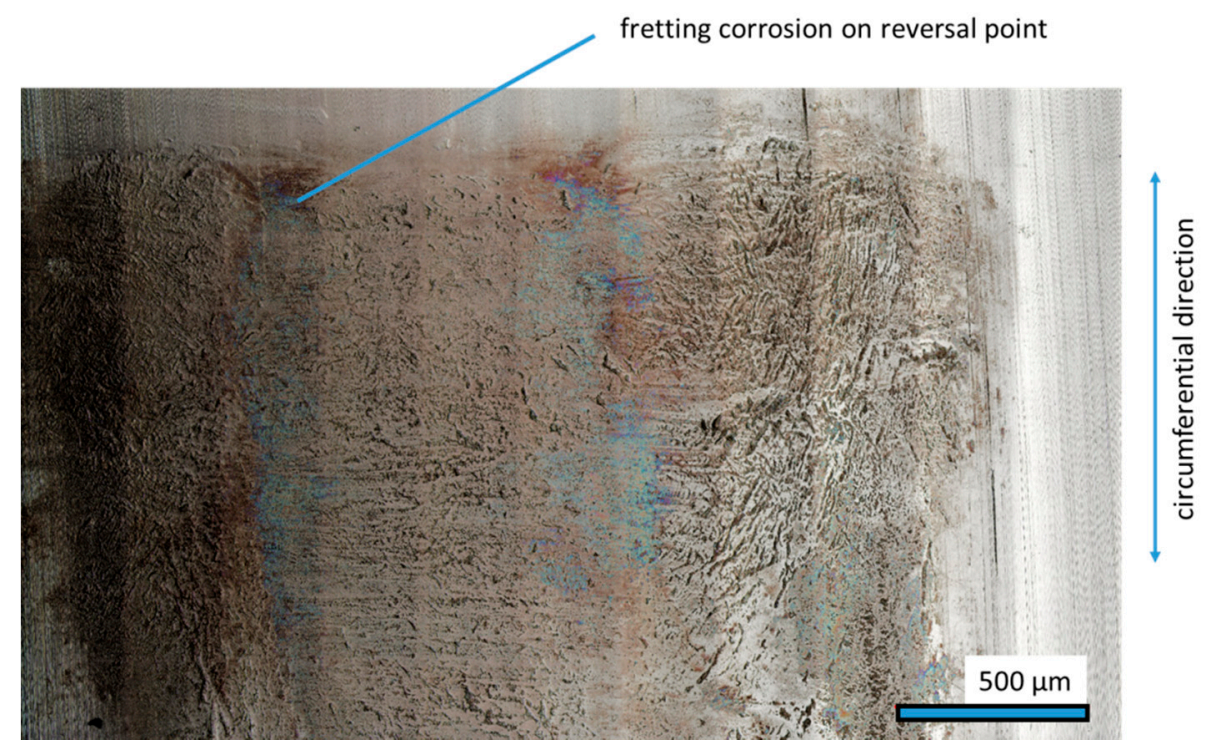

Figure 8. Raceway surface on reversal point for grease-lubricated bearing after more than 1 million oscillating cycles, the formation of tribofilm and fretting corrosion.

In addition, bearings with graphene grease lubrication were tested for more than 1 million test cycles. A reversal point on a bearing tested with a mixture of grease and graphene platelets with a thickness of 11-15 $\mathrm{nm}$ is shown in Figure 9. At the reversal point, only minor color changes can be seen on the surface. Small dark spots are visible on the raceway itself, but there are no signs of wear due to the mixed lubrication conditions. In this instance, the graphene platelets seem to have a positive effect on the lubrication conditions at the reversal points. A detailed view of the raceway shows that the surface appearance changed to a darker color due to the graphene (Figure 10). There are no additional sights of tribofilm formation or corrosion on the surface.

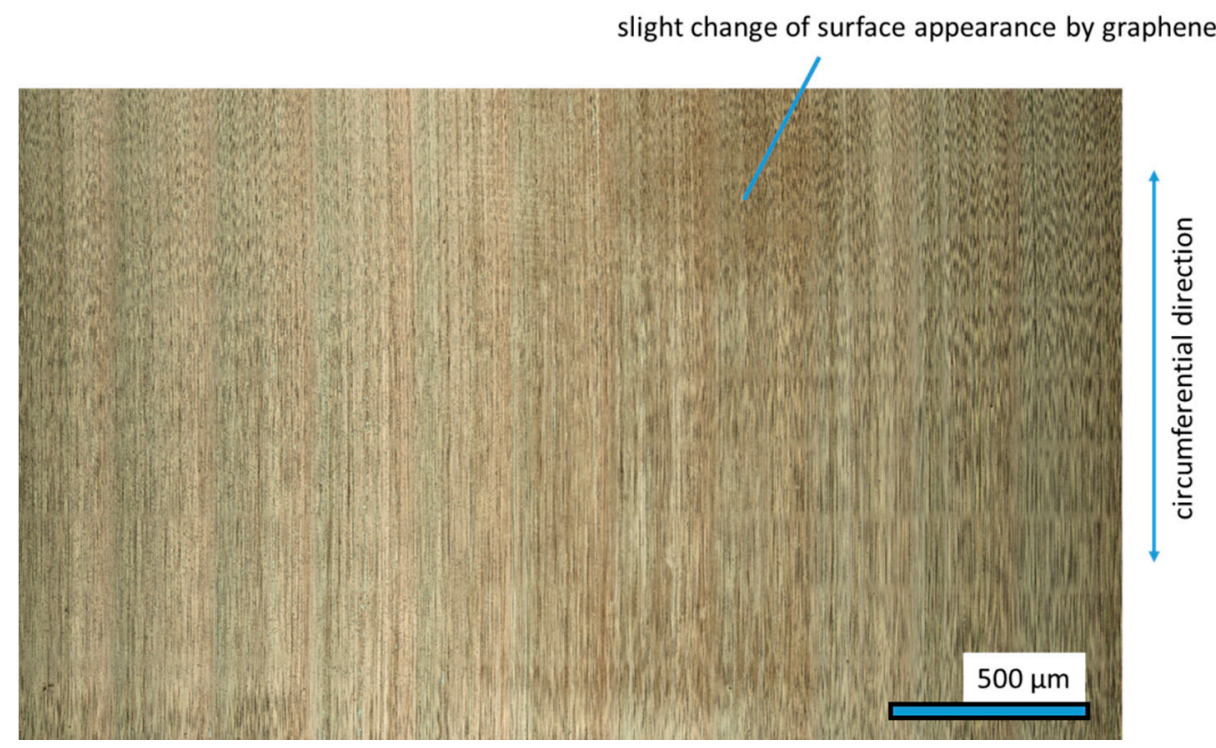

Figure 9. Raceway surface on reversal point for graphene grease-lubricated bearing after more than 1 million oscillating cycles, thickness of graphene platelets $11-15 \mathrm{~nm}$. 


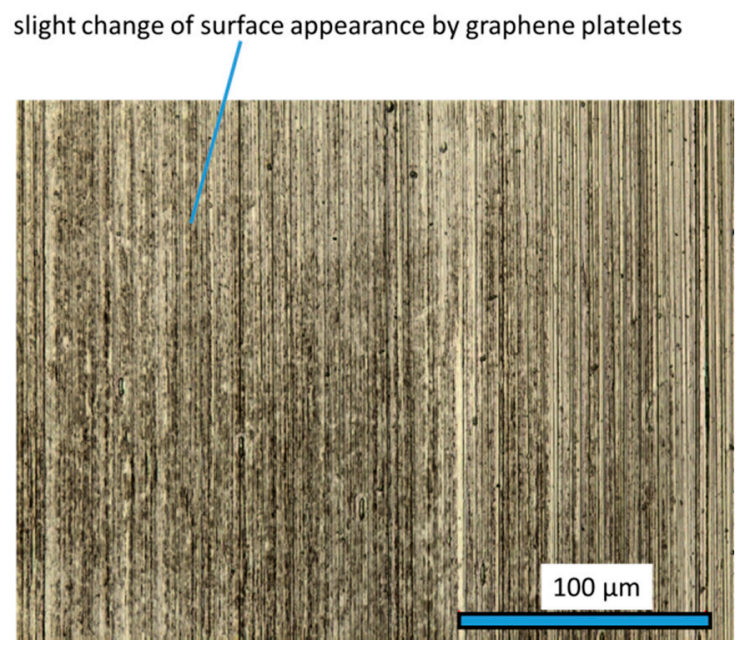

Figure 10. Detailed view: raceway surface of reversal point for graphene grease-lubricated bearing after more than 1 million oscillating cycles, thickness of graphene platelets 11-15 nm.

The graphene dry-lubricated bearings have also been tested for more than 1 million test cycles. A reversal point on the raceway is shown in Figure 11 for a bearing with graphene platelets with a thickness of 11-15 nm. Some graphene agglomerates are stitched to the surface and the surface itself is a darker color compared to the original bearing surface. On the reversal point, a thin, black graphene-based film is formed. Besides the raceway, graphene formed a zone of compressed particles. Wear could not be detected on the original bearing surface. Figure 12 shows a closer view on the graphene film formed on the reversal point. A thicker graphene film formed on the asperities. On the suppressions, a darker color compared to the bearing steel proves that graphene covers the surface. A detailed view of the surface of a roller is given in Figure 13. On the surface pattern of smeared graphene, agglomerates can be found serving as a dry lubricant.

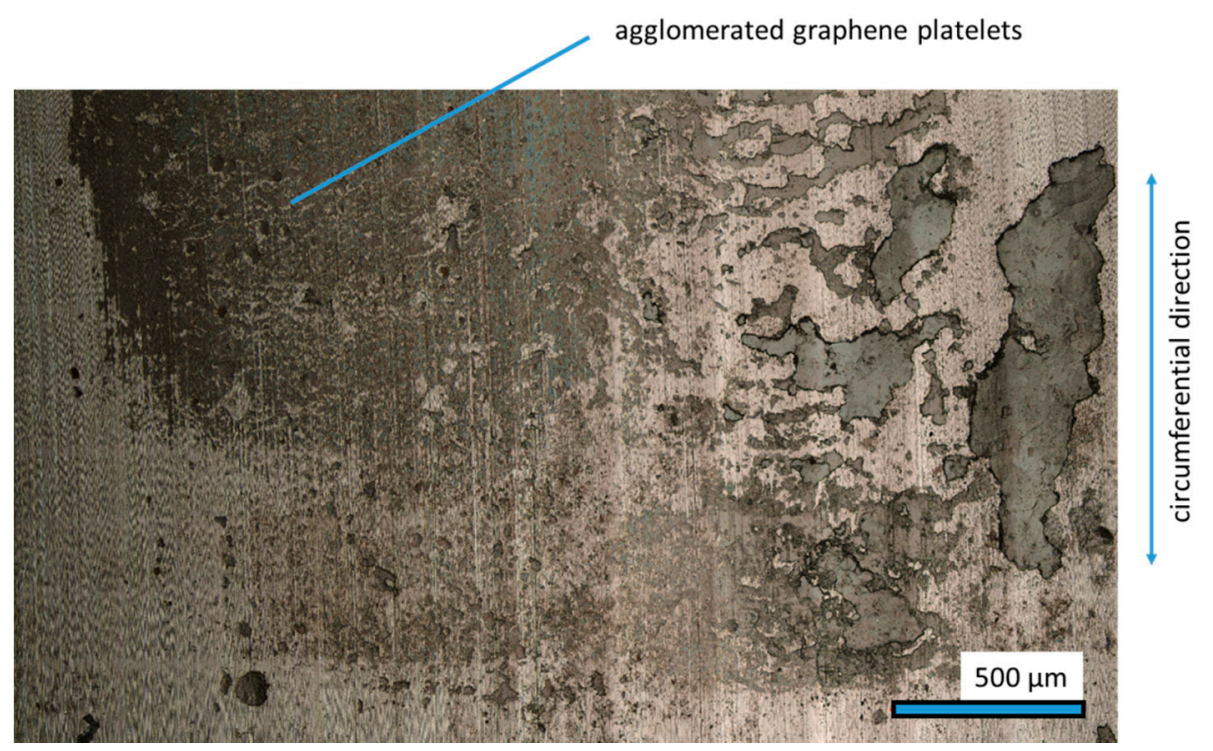

Figure 11. Raceway surface of the reversal point for graphene dry-lubricated bearings after more than 1 million oscillating cycles, thickness of graphene platelets $11-15 \mathrm{~nm}$. 


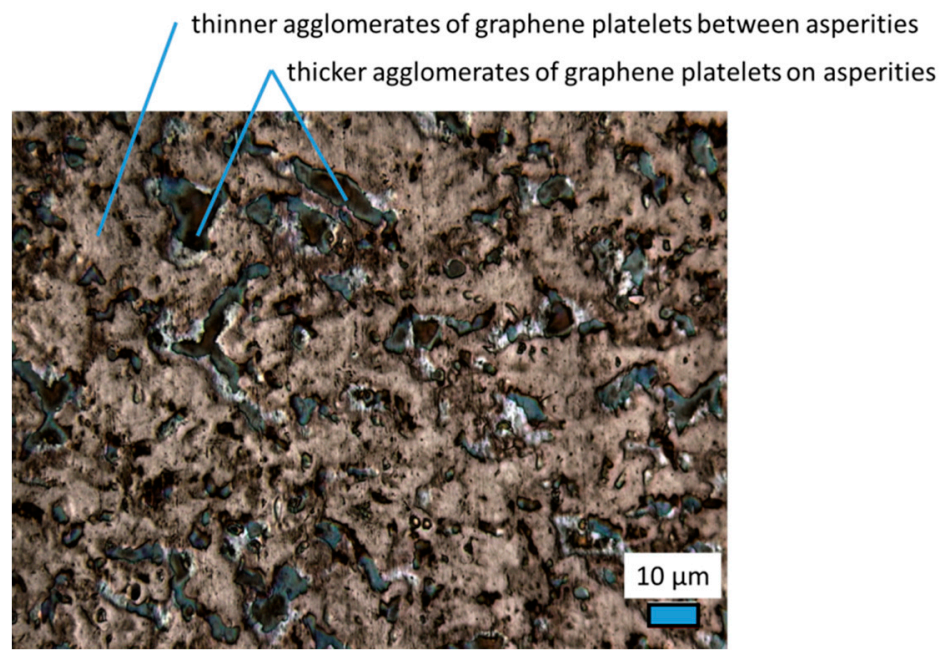

Figure 12. Detailed view: raceway surface on the reversal point for graphene dry-lubricated bearings after more than 1 million oscillating cycles, thickness of graphene platelets $11-15 \mathrm{~nm}$.

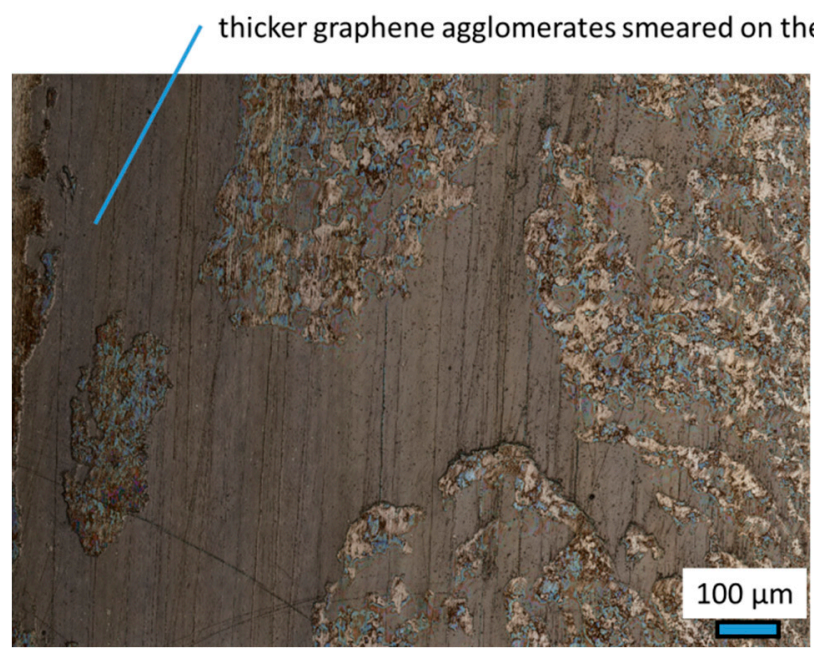

Figure 13. Detailed view: roller surface for graphene dry-lubricated bearing after more than 1 million oscillating cycles, thickness of graphene platelets 11-15 nm.

The benefit of the application of the graphene platelets as a dry lubricant seems to be that the graphene agglomerates on the surface are compressed by the rolling motion. The mechanism is illustrated in Figure 14. Due to the ability of the platelets to cover the roughness asperities, solid metallic contact can be avoided. Thus, the rolling and sliding motion of the ball happens on a thin, protective film with a height in the $10 \mathrm{~nm}$ range. The graphene layers seem to wear very slowly and remain stable under the higher loads that can be found in a typical rolling bearing application. Besides this, the graphene coating prevents the surface from oxidizing due to passivation effects. On the investigated bearings that were dry-lubricated with graphene, no oxidation was obvious, even months after the tests. The anti-corrosive effect of graphene was also observed by Rosaldo [25]. 

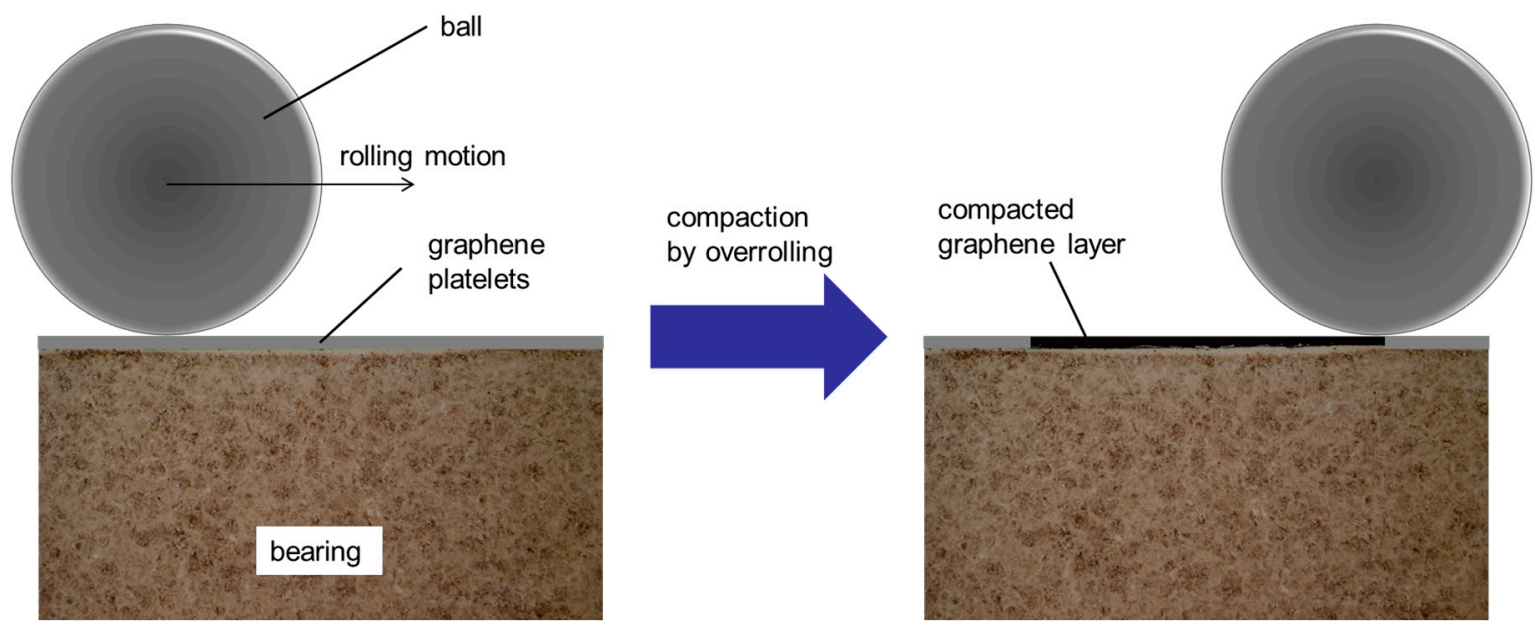

Figure 14. Graphene plateletes as a dry lubricant in rolling contact-compaction of functionalized graphene agglomerates.

\section{Discussion}

The feasibility of applying graphene platelets as grease additives and as a dry lubricant could be demonstrated. The graphene platelets could significantly influence the rolling contact under reciprocating motion by reducing the friction and minimizing surface wear.

The graphene platelets offer favorable sliding planes, allowing the reduction of friction losses in solid contacts. It could be proven that the thickness of the graphene layers clearly influences the friction. Figure 15 summarizes the influence of the graphene platelets of different thicknesses. Graphene platelets with an average thickness of 6-8 nm featured the highest reduction of friction as a dry lubricant as well as an additive to grease. Very thin graphene platelets also have beneficial sliding properties, but the influence is not as high as it is for thicker graphene. It can be conjectured that thinner graphene layers cover the bearing surface but feature less favorable sliding planes in between the platelets. In the case of thicker graphene, less beneficial sliding planes between the platelets also seem to occur, as fewer platelets are in the contacting zone. Also, graphite nanoparticles can act as a dry lubricant as well as a beneficial grease additive. In the case of the graphite particles, the compressed surface film features favorable sliding planes and worn particles can act as a third body in the contact.

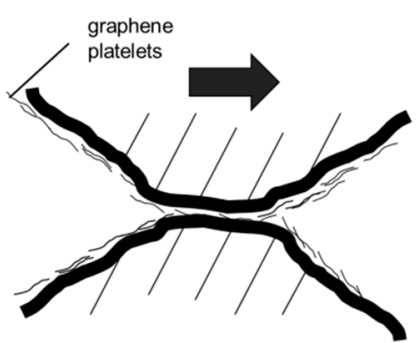

(a)

graphene platelets of low thickness

$>$ separation via sliding planes not sufficient (compared to thicker graphene platelets) $>$ covers surface as dry lubricant and as grease additive

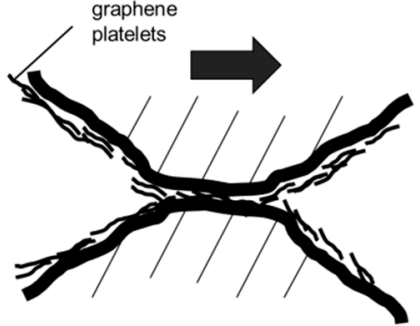

(b)

graphene platelets of medium thickness

$>$ separation via sliding planes between platelets sufficient $>$ Lowest CoF in case of graphene platelets with thickness in medium range $>$ covers surface as dry lubricant and as grease additive

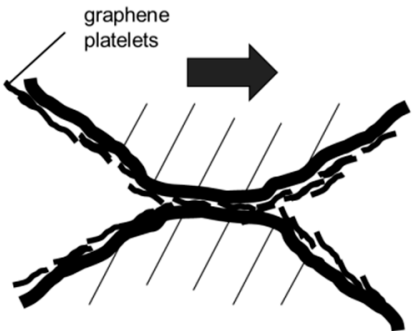

(c)

graphene platelets of high thickness

$>$ seem to feature less sliding planes between platelets compared to graphene with medium thickness $>$ covers surface as dry lubricant and as grease additive

Figure 15. Influence of graphene platelets' thickness on frictional properties. 
How the influence of the graphene platelets on the friction is related to the surface roughness has yet to be clarified in further studies. The dispersion of the graphene and graphite nanoparticles into the grease also should be enhanced in future work. The influence of the graphene as a grease additive has yet to be investigated regarding the specific additive packages and the influence of the tribofilm formation.

\section{Conclusions}

It could be shown that graphene platelets as a dry lubricant and also as a grease additive exhibit excellent wear resistance in rolling contacts under reciprocating motion. Compared to pure grease lubrication, the friction could be significantly reduced for all tested graphene platelet thicknesses, as well as for the spherical graphite nano-particles. The graphene platelets offer favorable sliding planes and reduce friction loss in solid contacts. This can be ascribed to the ability of the platelets to cover surface asperities featuring favorable sliding planes. It can be concluded that the graphene layer can also be used for bearings without increased bearing clearance. As the bearing surfaces showed no wear during the test phase, it can be expected that the graphene platelets create a very thin protective layer on the surface. This thin overcoat seems to feature a high wear resistance and protects the surface from oxidation.

Furthermore, the tribometer experiments show that graphene platelets cause friction to decrease at lower sliding speeds. This leads to the conclusion that the sliding planes of the graphene platelets have a clear influence on the mixed lubrication conditions. In the sliding tests, the graphene platelets showed superior behavior for low sliding speeds compared to the graphite nano spheres, as the surface is covered by the 2-D structure of the platelets. Thus, the surface asperities are covered and solid metallic contacts can be avoided.

This work shows that graphene platelets as 2-D materials are suitable for lubrication (dry, but also as a grease additive) in rolling bearings which are operated under a pivoting motion. Ongoing studies should also gain insight on the application of graphene platelets for lubrication in rotating applications. A possible application can be found in constant velocity join shafts or robot arms. The excellent properties of graphene, which have so far proven themselves in nano and micro test benches, have been transferred to macroscopic applications, such as those found in various machine elements. The use of graphene platelets as a grease additive or as a dry lubricant leads to a reduction in friction and wear, which is essential for saving resources.

Author Contributions: F.P. wrote this article, performed the processes and measurements, and analyzed its results. G.P. supervised the work and provided suggestions for the final discussion. All authors have read and agreed to the published version of the manuscript.

Funding: This research received no external funding.

Conflicts of Interest: The authors declare no conflict of interest.

\section{References}

1. Ghosh, S.; Calizo, I.; Teweldebrhan, D.; Pokatilov, E.P.; Nika, D.L.; Balandin, A.A.; Bao, W.; Miao, F.; Lau, C.N. Extremely high thermal conductivity of graphene: Prospects for thermal management applications in nanoelectronic circuits. Appl. Phys. Lett. 2008, 92, 151911/1-151911/3. [CrossRef]

2. Marinho, B.; Ghislandi, M.; Tkalya, E.; Koning, C.E.; de With, G. Electrical conductivity of compacts of graphene, multi-wall carbon nanotubes, carbon black, and graphite powder. Powder Technol. 2012, 221, 351-358. [CrossRef]

3. Berman, D.; Erdemir, A.; Sumant, A.V. Reduced wear and friction enabled by graphene layers on sliding steel surfaces in dry nitrogen. Carbon 2013, 59, 167-175. [CrossRef]

4. Berman, D.; Erdemir, A.; Sumant, A.V. Graphene: A new emerging lubricant. Mater. Today 2014, 17, 31-42. [CrossRef]

5. Marchetto, D.; Held, C.; Hausen, F.; Wählisch, F.; Dienwiebel, M.; Bennewitz, R. Friction and Wear on Single-Layer Epitaxial Graphene in Multi-Asperity Contacts. Tribol. Lett. 2012, 48, 77-82. [CrossRef] 
6. Kim, K.-S.; Lee, H.-J.; Lee, C.; Lee, S.-K.; Jang, H.; Ahn, J.-H.; Kim, J.-H.; Lee, H.-J. Chemical Vapor Deposition-Grown Graphene: The Thinnest Solid Lubricant. ACS Nano 2011, 5, 5107-5114. [CrossRef]

7. Feng, X.; Kwon, S.; Park, J.Y.; Salmeron, M. Superlubric Sliding of Graphene Nanoflakes on Graphene. ACS Nano 2013, 7, 1718-1724. [CrossRef]

8. $\quad \mathrm{Xu}, \mathrm{L} . ; \mathrm{Ma}, \mathrm{T} .-\mathrm{B} . ; \mathrm{Hu}, \mathrm{Y} .-\mathrm{Z} . ;$ Wang, H. Vanishing stick-slip friction in few-layer graphenes: The thickness effect. Nanotechnology 2011, 22. [CrossRef]

9. Penkov, O.; Kim, H.-J.; Kim, H.J.; Kim, D.-E. Tribology of Graphene: A Review. Int. J. Precis. Eng. Manuf. 2014, 15, 577-585. [CrossRef]

10. Frank, I.W.; Tanenbaum, D.M.; van der Zande, A.M.; McEuen, P.L. Mechanical properties of suspended graphene sheets. J. Vac. Sci. Technol. B Microelectron. Nanometer Struct. Process. Meas. Phenom. 2007, 25, 2558-2561. [CrossRef]

11. Restuccia, P.; Righi, M.C. Tribochemistry of graphene on iron and its possible role in lubrication of steel. Carbon 2016, 106, 118-124. [CrossRef]

12. Won, M.-S.; Penkov, O.V.; Kim, D.-E. Durability and degradation mechanism of graphene coatings deposited on Cu substrates under dry contact sliding. Carbon 2013, 54, 472-481. [CrossRef]

13. Paredes, J.I.; Villar-Rodil, S.; Martínez-Alonso, A.; Tascon, J.M.D. Graphene Oxide Dispersions in Organic Solvents. Langmuir 2008, 24, 10560-10564. [CrossRef] [PubMed]

14. Li, Z.; Xu, C.; Xiao, G.; Zhang, J.; Chen, Z.; Yi, M. Lubrication Performance of Graphene as Lubricant Additive in 4-n-pentyl-4'-cyanobiphyl Liquid Crystal (5CB) for Steel/Steel Contacts. Materials 2018, 11, 2110. [CrossRef] [PubMed]

15. Senatore, A.; D'Agostino, V.; Petrone, V.; Ciambelli, P.; Sarno, M. Graphene oxide nanosheets as effective friction modifier for oil lubricant: Materials, methods, and tribological results. ISRN Tribol. 2013, 2013, 425809. [CrossRef]

16. Guo, Y.-B.; Zhang, S.-W. The Tribological Properties of Multi-Layered Graphene as Additives of PAO2 Oil in Steel-Steel Contacts. Lubricants 2016, 4, 30. [CrossRef]

17. Zhang, W.; Zhou, M.; Zhu, H.; Tian, Y.; Wang, K.; Wei, J.; Ji, F.; Li, X.; Li, Z.; Zhang, P.; et al. Tribological properties of oleicacid-modified graphene as lubricantoil additives. J. Phys. D Appl. Phys. 2011, 44, 205303. [CrossRef]

18. Singh, J.; Anand, G.; Kumar, D.; Tandon, N. Graphene based composite grease for elastohydrodynamic lubricated point contact. IOP Conf. Ser. Mater. Sci. Eng. 2016, 149, 012195. [CrossRef]

19. Missala, T.; Szewczyk, R.; Winiarski, W.; Hamela, M.; Kamiński, M.; Dabrowski, S.; Pogorzelski, D.; Jakubowska, M.; Tomasik, J. Study on Tribological Properties of Lubricating Grease with Additive of Graphene. In Progress in Automation, Robotics and Measuring Techniques, Advances in Intelligent Systems and Computing; Szewczyk, R., Ed.; Springer International Publishing: Cham, Switzerland, 2015; Volume 352, pp. 181-187. [CrossRef]

20. Liu, L.; Zhou, M.; Jin, L.; Li, L.; Mo, Y.; Su, G.; Li, X.; Zhu, H.; Tian, Y. Recent advances in friction and lubrication of graphene and other 2D materials: Mechanisms and applications. Friction 2019, 7, 199-216. [CrossRef]

21. Kumar, P.; Wani, M.F. Synthesis and tribological properties of graphene: A review. J. Tribol. 2017, 13, 36-71.

22. Pape, F.; Knigge, S.R.; Glasmacher, B.; Poll, G. Graphene based dry lubrication in rolling contacts. In Proceedings of the Lubmat 2018, San Sebastian, Spain, 5-6 June 2018.

23. Pape, F.; Poll, G. Graphenbasierte Schmierung von Wälzlagern. Tribol. Und Schmier. 2019, 66, $26-31$. [CrossRef]

24. Pape, F.; Rissing, L.; Gatzen, H.H. Fabrication and Tribological Investigation of Fullerene C60/C70 Reinforced Epoxy Resin SU-8 ${ }^{\mathrm{TM}}$. In Proceedings of the 51st Tribologie Fachtagung 2010, Göttingen, Germany, 27-29 September 2010; Gesellschaft für Tribologie e.V.: Göttingen, Germany, 2010; pp. 06/1-06/11, ISBN 978-3-00-032180-1.

25. Sandoz-Rosaldo, E.J. The tribological behavior of graphene and its role as a protective coating. Mater. Sci. 2013. [CrossRef]

(C) 2019 by the authors. Licensee MDPI, Basel, Switzerland. This article is an open access article distributed under the terms and conditions of the Creative Commons Attribution (CC BY) license (http://creativecommons.org/licenses/by/4.0/). 